\title{
Phytosterol-enriched products on the Irish market: examination of intake and consumption patterns
}

\author{
Áine Hearty*, Edel Duffy, Jennifer Joyce, Caitriona O'Connor and Michael J Gibney \\ Institute of Food and Health, Room 3.02C, UCD Agriculture and Food Science Centre, School of Agriculture, \\ Food Science \& Veterinary Medicine, University College Dublin, Belfield, Dublin 4, Ireland
}

Submitted 8 March 2007: Accepted 19 December 2007: First published online 29 February 2008

\begin{abstract}
Objective: To study patterns of phytosterol intakes in the Irish population from enriched sources.

Design: An interview-assisted questionnaire, which recorded information on sociodemographics, product types, intake amounts and patterns of intake. Independent samples $t$ tests, one-way ANOVA and cross-tabulations were used to establish significant relationships between groups of variables. The top tertile of phytosterol intakes was also calculated.

Setting: Point-of-purchase of phytosterol-enriched products in Irish supermarkets. Subjects: Four hundred and sixty-eight consumers (186 men and 282 women) of phytosterol-enriched foods.

Results: The mean phytosterol intake from enriched sources for the sample population was $2 \cdot 45 \mathrm{~g} / \mathrm{d}$. Men had greater intakes than women $(2 \cdot 71 \mathrm{~g} / \mathrm{d} v .2 \cdot 29 \mathrm{~g} / \mathrm{d}$, respectively). A total of $62 \%$ of consumers were unaware of the importance of consuming fruit and vegetables while taking these products. The majority of respondents reported that they had high cholesterol (61\%) and $22 \%$ of consumers also took cholesterol-lowering medication (statins). In total, 23\% had phytosterol intakes $>3.0 \mathrm{~g} / \mathrm{d}$ and the majority of consumers (58\%) had been consuming these products for $>1$ year. The mean intake for respondents with phytosterol intakes $>3 \cdot 0 \mathrm{~g} / \mathrm{d}$ was $4 \cdot 1 \mathrm{~g} / \mathrm{d}$ and $74 \%$ of this subgroup had been consuming these products for $>1$ year.

Conclusion: In general, phytosterol intakes are within efficacious levels in the Irish population. However, there appears to be a subgroup that has been consuming these products at intakes greater than current recommendations for $>1$ year.
\end{abstract}

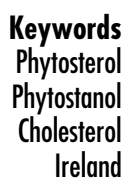

For over 50 years it has been known that phytosterols lower blood cholesterol levels by blocking the absorption of cholesterol in the gut, although the exact mechanism is not fully understood ${ }^{(1)}$. There is substantial evidence from a vast number of studies that phytosterols lower total and LDL cholesterol levels ${ }^{(2-5)}$. Phytosterols are naturally occurring plant compounds that are extracted and esterified before incorporation into foodstuffs, and these enriched products were first marketed for the lowering of cholesterol in $1995^{(6)}$. Some plant sterols currently in use are hydrogenated before esterification, resulting in saturated stanol derivatives or 'plant stanols', such as $\beta$-sitostanol and campestanol ${ }^{(3)}$. For the purpose of the present paper, 'phytosterol' refers to both plant sterols and plant stanols. Studies have shown that a reduction in blood cholesterol can be achieved by daily consumption of $1 \cdot 5-3.0 \mathrm{~g}$ phytosterols and these intakes typically result in a reduction in serum total cholesterol by $8-17 \%$ and of LDL cholesterol by $6-15 \%{ }^{(6-8)}$.
Over the past few years, a wide range of food products containing phytosterols have become available on the European market. As part of authorising the placing on the market of 'yellow fat spreads with added phytosterols' as novel foods or food ingredients (EU Novel Food Regulation 258/97/EC), the Scientific Committee for Food (SCF) recommended conduction of post-launch monitoring (PLM) to establish if these products are reaching the appropriate target groups and if use of the products is as predicted ${ }^{(9)}$. This PLM scheme was applied to phytosterol-enriched spreads manufactured by Unilever via consumer telephone care lines and market surveys. The aim of the Unilever study was to obtain data on consumption and possible side-effects of the enriched spreads. Information was gathered on real purchase data from consumers in 2001 in The Netherlands, UK, France, Germany and Belgium. In another more recent study, the effectiveness of customary use of phytosterol/stanolenriched margarines on blood cholesterol was examined 
in free-living conditions with data from the Dutch Doetinchem cohort $^{(10)}$. This was the first report to find a modest beneficial effect on blood cholesterol level under customary conditions; however, intakes of enriched spread were found to be lower than predicted (i.e. 9-15 g/d).

Phytosterol-enriched products are relatively new to the market, especially products such as enriched yoghurt drinks and milks. Therefore PLM is still in its early stages with respect to understanding patterns of consumption of these products, and studies such as the present one on customary intake patterns are only just beginning to appear in the literature. PLM studies provide valuable information with respect to consumer consumption patterns, which are used to complement, not replace, pre-market safety evaluation studies. The potential exists that these products could be consumed in amounts above recommended levels or indeed below minimum effective doses, and relatively little information is available on patterns of usage of these products in terms of period of consumption, intake of multiple product types and actual amounts consumed in free-living individuals. Therefore the aim of the present study was to explore consumption patterns and estimate intakes of phytosterols from all enriched sources on the Irish market.

\section{Methods}

\section{Study sample and data collection}

A sample population of 468 consumers of phytosterolenriched products ( 186 men and 282 women) took part in the survey conducted between September and October 2005. All respondents were required to be consuming phytosterol-enriched foods or have another member in their household consuming the products. The participants were recruited on a voluntary basis in thirteen supermarkets in the Republic of Ireland, at the point of purchase. The supermarkets were located in either a major urban location on the east coast or in a more rural location in the south west, in different socio-economic catchment areas, and sampling took place at varying times throughout the day on all days of the week.

\section{Questionnaire design}

Data were collected using an interviewer-assisted questionnaire. A series of closed-ended questions was used to estimate intakes of phytosterols from enriched sources. Each respondent was provided with a comprehensive list of all phytosterol-enriched products available on the Irish market. They were asked details about the brands and product types they consumed, how often they usually consumed them (i.e. times per day and days per week), the quantity of each product consumed in terms of portion size, and the length of time they had been a consumer of these products (in months). Participants were shown photographs of all available products and of portion sizes of each product type, so that they could estimate the amount of each enriched product they consumed. Information on the consumption of both phytosterol- and phytostanol-enriched products was collected; however, the present study collectively refers to these as 'phytosterols'. There were five enriched product types on the Irish market at the time of the study, i.e. spreads, one-a-day yoghurt drinks, yoghurts, milk and cheese spread, and all of these were examined. Data were collected at brand level to ensure that accurate information on phytosterol concentrations was used in the calculations. In relation to reasons for consumption of the products, respondents were asked whether they consumed the products owing to a diagnosed medical condition and, if so, to specify what the condition was. If they had a medical condition (e.g. high cholesterol), they were also asked whether they took medication for it. Information was also gathered on social and demographic characteristics, on reading of product labels, and on consumption of fruit and vegetables.

\section{Data analysis}

Phytosterol concentrations per brand per product type were obtained both from the product label and the relevant product manufacturers. Intakes of phytosterols were calculated for each respondent from this information based on the quantity and frequency data collected in the questionnaire. Categories were created for the following variables: gender, age group, education level, period of consumption and the number of days per week the products were consumed. The levels of calculated phytosterol intake were divided into three categories related to the efficacy for lowering cholesterol based on the SCF recommendations ${ }^{(11)}$ : suboptimal intakes $(<1.5 \mathrm{~g} / \mathrm{d})$, optimal intakes $(1.5-3.0 \mathrm{~g} / \mathrm{d})$ and higher intakes $(>3.0 \mathrm{~g} / \mathrm{d})$. The SCF has concluded there is no evidence of additional benefits of phytosterols at intakes greater than $3.0 \mathrm{~g} / \mathrm{d}$ and that high intakes might induce undesirable effects, so it is therefore prudent to avoid plant sterol intakes exceeding $3 \cdot 0 \mathrm{~g} / \mathrm{d}^{(11)}$.

Data were analysed using the Statistical Package for the Social Sciences statistical software program version 12 for Windows $^{\mathrm{TM}}$ (SPSS Inc., Chicago, IL, USA). Analyses of intakes of phytosterols were completed using descriptive statistics. Tests for significance were completed with Pearson $\chi^{2}$ analysis, independent samples $t$ tests and oneway ANOVA. Post hoc tests were completed with the least significant difference test and the significance level was set at $P<0 \cdot 05$. Results were generated separately for the total population, consumers only, consumers of one product type only, respondents who were also taking statin drugs and respondents who had phytosterol intakes $>3 \cdot 0 \mathrm{~g} / \mathrm{d}$. 


\section{Results}

A total of $377(81 \%)$ respondents were self-reporters, while ninety-one (19\%) questionnaires were reported by another member of the household. Mean phytosterol intakes from enriched sources were not found to be significantly different between the two groups $(2.42 \mathrm{~g} / \mathrm{d}$ self-reported $v \cdot 2 \cdot 59 \mathrm{~g} / \mathrm{d}$ reported by other, $P>0.05)$. Therefore all respondents' results were analysed together.

Total phytosterol intakes (means with their standard deviation, minimum, maximum and 90th, 95th and 97.5th percentiles) from enriched sources for the sample of Irish adults are shown in Table 1 . In total, 468 subjects participated in this study (186 men and 282 women). The mean phytosterol intake was $2 \cdot 45 \mathrm{~g} / \mathrm{d}$ with a range of $0 \cdot 21-9 \cdot 84 \mathrm{~g} / \mathrm{d}$. At the 90th percentile, the intake of phytosterols was $4.41 \mathrm{~g} / \mathrm{d}$, while intake at the 97.5 th percentile was $6 \cdot 61 \mathrm{~g} / \mathrm{d}$. Men had a significantly higher phytosterol intake than women $(2 \cdot 71 \mathrm{~g} / \mathrm{d} \quad v \cdot 2 \cdot 29 \mathrm{~g} / \mathrm{d}$ respectively, $P<0 \cdot 001)$. There were no significant differences in intake of phytosterols from enriched products across the age groups. In relation to education level, phytosterol intake was lower in individuals who completed third level $(2 \cdot 14 \mathrm{~g} / \mathrm{d})$ compared with those who completed primary $(2 \cdot 81 \mathrm{~g} / \mathrm{d})$ and secondary level $(2.57 \mathrm{~g} / \mathrm{d}) \quad(P<0 \cdot 05)$. Over half of the respondents reported being introduced to phytosterol-enriched products through advertising and 14.5\% were introduced by their doctor. However, phytosterol intakes were greater in individuals who were introduced by a doctor than in those introduced through advertising $(2 \cdot 90 \mathrm{~g} / \mathrm{d} v .2 \cdot 38 \mathrm{~g} / \mathrm{d}$ respectively, $P<0 \cdot 05)$. The majority of subjects $(60 \cdot 7 \%)$ reported consuming phytosterol-enriched foods due to diagnosis of high cholesterol, while $36 \cdot 3 \%$ of those surveyed were consuming phytosterol-enriched foods in the absence of a medical condition. It was found that respondents reporting high cholesterol had greater intakes than those with no medical condition $(2.63 \mathrm{~g} / \mathrm{d} v$. $2 \cdot 13 \mathrm{~g} / \mathrm{d}$ respectively, $P<0 \cdot 05)$.

Phytosterol intakes were divided into three categories: suboptimal intakes $(<1.5 \mathrm{~g} / \mathrm{d})$, optimal intakes $(1 \cdot 5-3.0 \mathrm{~g} / \mathrm{d})$ and higher intakes $(>3.0 \mathrm{~g} / \mathrm{d})$, and the characteristics of intakes of phytosterol-enriched products were compared across these groups (Table 2). The majority of respondents ( $54 \%$ ) had optimal intakes, while $23 \%$ had suboptimal intakes and $23 \%$ had intakes above the recommended range. The respondents were asked about the period of consumption (i.e. how long prior to the interview had they been consumers of phytosterolenriched products) and also how many days per week that they consumed these products. It was found that $58 \%$ reported consuming these products for $>1$ year, and the majority reported consuming them every day (90\%). People who consumed the products for $>1$ year were more likely to have intakes above the recommended range than consumers for $<1$ year $(P<0 \cdot 0005)$. The majority of subjects consumed only one product type per day (69\%), $27 \%$ consumed two product types daily while

Table 1 Description of phytosterol intakes of the population sample: Irish consumers of phytosterol-enriched products, 2005

\begin{tabular}{|c|c|c|c|c|c|c|c|c|c|}
\hline \multirow[b]{2}{*}{ Variable } & \multirow[b]{2}{*}{$n$} & \multirow[b]{2}{*}{$\%$} & \multicolumn{7}{|c|}{ Phytosterol intake $(\mathrm{g} / \mathrm{d})$} \\
\hline & & & Mean & $\mathrm{SD}$ & Min & Max & P90 & P95 & $\mathrm{P} 97 \cdot 5$ \\
\hline Total & 468 & 100 & $2 \cdot 45$ & $1 \cdot 46$ & $0 \cdot 21$ & $9 \cdot 84$ & $4 \cdot 41$ & $5 \cdot 48$ & $6 \cdot 61$ \\
\hline \multicolumn{10}{|l|}{ Gender } \\
\hline Male & 186 & $39 \cdot 7$ & $2 \cdot 71^{*}$ & $1 \cdot 50$ & $0 \cdot 25$ & $8 \cdot 90$ & $4 \cdot 61$ & $5 \cdot 91$ & $6 \cdot 91$ \\
\hline Female & 282 & $60 \cdot 3$ & $2 \cdot 29$ & $1 \cdot 41$ & $0 \cdot 21$ & $9 \cdot 84$ & $3 \cdot 97$ & $5 \cdot 25$ & $6 \cdot 34$ \\
\hline \multicolumn{10}{|l|}{ Age group } \\
\hline$\leq 45$ years & 89 & $19 \cdot 0$ & $2 \cdot 17^{\mathrm{NS}}$ & $1 \cdot 36$ & $0 \cdot 28$ & $8 \cdot 90$ & $3 \cdot 92$ & $5 \cdot 43$ & $6 \cdot 27$ \\
\hline $46-65$ years & 263 & $56 \cdot 2$ & $2 \cdot 50$ & $1 \cdot 48$ & $0 \cdot 21$ & $9 \cdot 84$ & $4 \cdot 22$ & $5 \cdot 42$ & $6 \cdot 92$ \\
\hline$>65$ years & 116 & $24 \cdot 8$ & $2 \cdot 57$ & $1 \cdot 47$ & $0 \cdot 28$ & $7 \cdot 88$ & $4 \cdot 76$ & $5 \cdot 73$ & $6 \cdot 45$ \\
\hline \multicolumn{10}{|l|}{ Level of education } \\
\hline Primary & 56 & $12 \cdot 0$ & $2 \cdot 81^{a}$ & $1 \cdot 81$ & $0 \cdot 70$ & $9 \cdot 84$ & $5 \cdot 30$ & $7 \cdot 05$ & $9 \cdot 01$ \\
\hline Secondary & 257 & $54 \cdot 9$ & $2 \cdot 57^{\mathrm{a}}$ & $1 \cdot 43$ & $0 \cdot 28$ & $7 \cdot 88$ & $4 \cdot 47$ & $5 \cdot 70$ & $6 \cdot 74$ \\
\hline Third level & 155 & $33 \cdot 1$ & $2 \cdot 14^{b}$ & $1 \cdot 30$ & $0 \cdot 21$ & $8 \cdot 90$ & $3 \cdot 51$ & $4 \cdot 54$ & $6 \cdot 00$ \\
\hline \multicolumn{10}{|c|}{ Method of introduction to products } \\
\hline Advertising & 249 & $53 \cdot 2$ & $2 \cdot 38^{\mathrm{ac}}$ & $1 \cdot 35$ & $0 \cdot 21$ & $9 \cdot 84$ & $3 \cdot 96$ & $4 \cdot 94$ & $5 \cdot 91$ \\
\hline Doctor & 68 & $14 \cdot 5$ & $2 \cdot 90^{\mathrm{b}}$ & $1 \cdot 72$ & $0 \cdot 49$ & $8 \cdot 90$ & $5 \cdot 61$ & $6 \cdot 26$ & $7 \cdot 52$ \\
\hline Dietitian & 16 & $3 \cdot 4$ & $2 \cdot 72^{\mathrm{abc}}$ & $1 \cdot 66$ & $0 \cdot 80$ & $7 \cdot 88$ & $5 \cdot 82$ & $7 \cdot 88$ & $7 \cdot 88$ \\
\hline Friend & 51 & $10 \cdot 9$ & $2 \cdot 71^{\mathrm{bc}}$ & $1 \cdot 61$ & 0.89 & $7 \cdot 43$ & $5 \cdot 39$ & $6 \cdot 58$ & $7 \cdot 27$ \\
\hline Other & 84 & $17 \cdot 9$ & $2 \cdot 11^{\mathrm{a}}$ & $1 \cdot 29$ & $0 \cdot 28$ & $6 \cdot 94$ & $3 \cdot 68$ & $4 \cdot 79$ & $6 \cdot 72$ \\
\hline \multicolumn{10}{|l|}{ Medical condition } \\
\hline None & 170 & $36 \cdot 3$ & $2 \cdot 13^{a}$ & $1 \cdot 32$ & $0 \cdot 28$ & $8 \cdot 90$ & $3 \cdot 73$ & $4 \cdot 67$ & $6 \cdot 75$ \\
\hline High cholesterol & 284 & $60 \cdot 7$ & $2 \cdot 63^{b}$ & $1 \cdot 49$ & $0 \cdot 21$ & $9 \cdot 84$ & $4 \cdot 65$ & $5 \cdot 68$ & $6 \cdot 49$ \\
\hline Heart disease & 8 & $1 \cdot 7$ & $2 \cdot 43^{a b}$ & $1 \cdot 14$ & $1 \cdot 47$ & $4 \cdot 94$ & $4 \cdot 94$ & $4 \cdot 94$ & $4 \cdot 94$ \\
\hline High blood pressure & 3 & 0.6 & $3 \cdot 20^{a b}$ & $2 \cdot 01$ & $2 \cdot 00$ & $5 \cdot 52$ & $5 \cdot 52$ & $5 \cdot 52$ & $5 \cdot 52$ \\
\hline Other medical condition & 3 & $0 \cdot 6$ & $3 \cdot 58^{a b}$ & $3 \cdot 06$ & $0 \cdot 89$ & $6 \cdot 90$ & $6 \cdot 90$ & $6 \cdot 90$ & $6 \cdot 90$ \\
\hline
\end{tabular}

P90, P95 and P97.5, 90th, 95th and $97 \cdot 5$ th percentile, respectively.

a,b,c Mean values within groups with unlike superscript letters were significantly different $(P<0.05)$.

${ }^{*}$ Mean value was significantly different compared with females (independent samples $t$ test): $P<0.001$. 
Table 2 Characteristics of the intake of phytosterol-enriched products according to level of daily phytosterol intake: Irish consumers of phytosterol-enriched products, 2005

\begin{tabular}{|c|c|c|c|c|c|c|c|c|c|}
\hline & \multicolumn{2}{|c|}{ Total } & \multicolumn{2}{|c|}{$<1.5 \mathrm{~g} / \mathrm{d}$} & \multicolumn{2}{|c|}{$1.5-3.0 \mathrm{~g} / \mathrm{d}$} & \multicolumn{2}{|c|}{$>3.0 \mathrm{~g} / \mathrm{d}$} & \multirow[b]{2}{*}{$P+$} \\
\hline & $n$ & $\%$ & $n$ & $\%$ & $n$ & $\%$ & $n$ & $\%$ & \\
\hline Total & 468 & $100 \cdot 0$ & 108 & $23 \cdot 0$ & 254 & $54 \cdot 0$ & 106 & $23 \cdot 0$ & \\
\hline \multicolumn{10}{|l|}{ Period of consumption } \\
\hline$<6$ months & 150 & $32 \cdot 1$ & 31 & $20 \cdot 7$ & 101 & $67 \cdot 3$ & 18 & $12 \cdot 0$ & \multirow[t]{3}{*}{$<0.0005$} \\
\hline $6-12$ months & 46 & $9 \cdot 8$ & 8 & $17 \cdot 4$ & 28 & $60 \cdot 9$ & 10 & $21 \cdot 7$ & \\
\hline$>1$ year & 272 & $58 \cdot 1$ & 69 & $25 \cdot 4$ & 125 & $46 \cdot 0$ & 78 & $28 \cdot 7$ & \\
\hline \multicolumn{10}{|c|}{ No. of days per week that products are consumed } \\
\hline $1-3 \mathrm{~d} /$ week & 22 & $4 \cdot 7$ & 6 & $27 \cdot 3$ & 13 & $59 \cdot 1$ & 3 & $13 \cdot 6$ & \multirow[t]{3}{*}{ NS } \\
\hline $4-6 \mathrm{~d} /$ week & 25 & $5 \cdot 3$ & 7 & $28 \cdot 0$ & 14 & $56 \cdot 0$ & 4 & $16 \cdot 0$ & \\
\hline $7 \mathrm{~d} /$ week & 421 & $90 \cdot 0$ & 95 & $22 \cdot 6$ & 227 & 53.9 & 99 & $23 \cdot 5$ & \\
\hline \multicolumn{10}{|c|}{ No. of product types consumed per day } \\
\hline 1 product/d & 323 & $69 \cdot 0$ & 106 & $32 \cdot 8$ & 192 & $59 \cdot 4$ & 25 & $7 \cdot 7$ & \multirow[t]{3}{*}{$<0.0005$} \\
\hline 2 products $/ d$ & 127 & $27 \cdot 1$ & 2 & $1 \cdot 6$ & 60 & $47 \cdot 2$ & 65 & $51 \cdot 2$ & \\
\hline 3 products $/ \mathrm{d}$ & 18 & $3 \cdot 8$ & 0 & $0 \cdot 0$ & 2 & $11 \cdot 1$ & 16 & $88 \cdot 9$ & \\
\hline \multicolumn{10}{|l|}{ Brand loyalty } \\
\hline Yes & 325 & $69 \cdot 4$ & 77 & $23 \cdot 7$ & 180 & $55 \cdot 4$ & 68 & $20 \cdot 9$ & \multirow[t]{2}{*}{ NS } \\
\hline No & 143 & $30 \cdot 6$ & 31 & $21 \cdot 7$ & 74 & $51 \cdot 7$ & 38 & $26 \cdot 6$ & \\
\hline \multicolumn{10}{|c|}{ Does the consumer read the label? } \\
\hline Yes & 289 & $61 \cdot 8$ & 68 & 23.5 & 165 & $57 \cdot 1$ & 56 & $19 \cdot 4$ & \multirow[t]{2}{*}{ NS } \\
\hline No & 179 & $38 \cdot 2$ & 40 & $22 \cdot 3$ & 89 & $49 \cdot 7$ & 50 & $27 \cdot 9$ & \\
\hline \multicolumn{10}{|c|}{ Awareness of importance of fruit and vegetables } \\
\hline Aware & 179 & $38 \cdot 2$ & 43 & $24 \cdot 0$ & 91 & $50 \cdot 8$ & 45 & $25 \cdot 1$ & \multirow[t]{2}{*}{ NS } \\
\hline Unaware & 289 & $61 \cdot 8$ & 65 & $22 \cdot 5$ & 163 & $56 \cdot 4$ & 61 & $21 \cdot 1$ & \\
\hline
\end{tabular}

tPearson $\chi^{2}$ test.

Table 3 Intake of phytosterols $(\mathrm{g} / \mathrm{d})$ from different product types for the total sample, and phytosterol intake from one product for its consumers only: Irish consumers of phytosterol-enriched products, 2005

\begin{tabular}{|c|c|c|c|c|c|c|c|c|c|c|}
\hline & \multicolumn{5}{|c|}{ Total sample $(\mathrm{g} / \mathrm{d})$} & \multicolumn{5}{|c|}{ Consumers only (g/d) } \\
\hline & Spreads & $\begin{array}{l}\text { Yoghurt } \\
\text { drinks }\end{array}$ & Yoghurts & Milk & $\begin{array}{l}\text { Cheese } \\
\text { spread }\end{array}$ & Spreads & $\begin{array}{l}\text { Yoghurt } \\
\text { drinks }\end{array}$ & Yoghurts & Milk & $\begin{array}{l}\text { Cheese } \\
\text { spread }\end{array}$ \\
\hline \multicolumn{11}{|l|}{ All products } \\
\hline$n$ & 468 & 468 & 468 & 468 & 468 & 320 & 272 & 79 & 16 & 9 \\
\hline Mean & $1 \cdot 33$ & $1 \cdot 14$ & $0 \cdot 14$ & 0.03 & 0.01 & $2 \cdot 73$ & $2 \cdot 80$ & $2 \cdot 60$ & $2 \cdot 70$ & $2 \cdot 38$ \\
\hline SD & $1 \cdot 39$ & 1.05 & 0.32 & $0 \cdot 17$ & 0.06 & $1 \cdot 66$ & 1.54 & 1.64 & $1 \cdot 26$ & $1 \cdot 22$ \\
\hline Min & 0.00 & 0.00 & 0.00 & 0.00 & 0.00 & $0 \cdot 21$ & $1 \cdot 03$ & 0.65 & $1 \cdot 18$ & 0.40 \\
\hline Max & $7 \cdot 84$ & $6 \cdot 00$ & $1 \cdot 60$ & $1 \cdot 50$ & 0.80 & $9 \cdot 84$ & 9.84 & 8.90 & $5 \cdot 60$ & $4 \cdot 46$ \\
\hline P90 & $2 \cdot 94$ & $2 \cdot 00$ & $0 \cdot 80$ & 0.00 & 0.00 & 4.94 & 4.94 & $5 \cdot 25$ & $5 \cdot 55$ & $4 \cdot 46$ \\
\hline \multicolumn{11}{|l|}{ One product only } \\
\hline$n$ & 148 & 116 & 6 & 0 & 1 & 148 & 116 & 6 & 0 & 1 \\
\hline$\%$ of consumers & $32+$ & 25 & 1 & 0 & 1 & $46 \ddagger$ & 43 & 8 & 0 & 11 \\
\hline Mean product intake & $28 \cdot 4$ & 1 yoghurt drink & 1 yoghurt & 0 & 10 & & & & & \\
\hline Mean & 1.99 & $1 \cdot 89$ & 0.80 & 0.00 & $0 \cdot 40$ & & & & & \\
\hline SD & $1 \cdot 16$ & 0.34 & 0.00 & 0.00 & 0.00 & & & & & \\
\hline
\end{tabular}

P90, 90th percentile.

tThis refers to the percentage of consumers of one product only from the total population; e.g. the percentage that only ate enriched spreads in the total population and did not consume any other enriched products.

$\ddagger$ This refers to the percentage of consumers of one product only from the number of consumers of the product; i.e. the percentage of consumers of spread from spread consumers only.

only $4 \%$ consumed three product types per day. Those who consumed three products per day were more likely to have phytosterol intakes $>3 \cdot 0 \mathrm{~g} / \mathrm{d}(P<0 \cdot 0005)$. When asked if they were loyal to the products, $69 \%$ reported they were brand loyal (i.e. they always choose the same product type and the same brand of the product). As advice regarding the consumption of these products is placed on the food label, respondents were asked if they actually read the label; $62 \%$ reported that they did.
However, when asked further questions about information contained on the label, only $38 \%$ were aware of the advice to regularly consume fruit and vegetables that is stated on the label.

The mean intake of phytosterols from the different product types available on the Irish market was examined for the total sample and for consumers only (Table 3). Spreads contributed the highest amount for the total population at $1.33 \mathrm{~g} / \mathrm{d}$. In terms of actual portion size, 
the mean consumption of enriched spreads for the total sample was $19 \mathrm{~g} / \mathrm{d}$. The contribution of phytosterols from one-a-day enriched yoghurt drinks was $1.14 \mathrm{~g} / \mathrm{d}$, while enriched yoghurts $(0.14 \mathrm{~g} / \mathrm{d})$, milk $(0.03 \mathrm{~g} / \mathrm{d})$ and cheese spreads $(0.01 \mathrm{~g} / \mathrm{d})$ contributed smaller amounts to the daily intake of phytosterols. Although the respondents were all consumers of phytosterol-enriched products, the intake of products varied. The product type with the highest probability of being consumed was enriched spreads ( $68 \%$ consumers), followed by one-a-day yoghurt drinks (58\%). Regarding total phytosterol intake for only consumers of each product, intakes were greatest from one-a-day yoghurt drinks $(2 \cdot 80 \mathrm{~g} / \mathrm{d})$, followed by spreads $(2 \cdot 73 \mathrm{~g} / \mathrm{d})$ and milk $(2 \cdot 70 \mathrm{~g} / \mathrm{d})$. To examine the intake of phytosterols among consumers of one product type only, portion sizes and their phytosterol intakes were estimated. Spreads and one-a-day yoghurt drinks were found to be the product types most likely to be consumed when no other phytosterol-enriched product was consumed. It was found that $32 \%$ of the sample consumed spreads only and no other product type (i.e. $46 \%$ of spread consumers) and $25 \%$ consumed one-a-day yoghurt drinks only (i.e. $43 \%$ of one-a-day yoghurt drink consumers). There were very few respondents who consumed enriched yoghurts or cheese spread only and none who consumed enriched milk only, indicating that these products are mainly consumed in combination with other product types by the same individual (i.e. a mixand-match pattern).

As the long-term implications of high phytosterol intakes are uncertain, consumers with phytosterol intakes higher than the SCF recommendations of $3.0 \mathrm{~g} / \mathrm{d}$ were examined separately; the results are presented in Table 4 . The mean phytosterol intake for this sample was 4.64 (SD 1.36$) \mathrm{g} / \mathrm{d}$. Spreads were consumed by $97 \%$ of this subgroup, providing a mean intake of $4.66(\mathrm{SD} 1.37) \mathrm{g} / \mathrm{d}$, and $75 \%$ consumed one-a-day yoghurt drinks, providing a mean intake of $4 \cdot 80(\mathrm{sD} 1.44) \mathrm{g} / \mathrm{d}$. Intakes were also examined across gender, age group, education level and medical condition, but no significant differences were observed (data not shown). Over $73 \%$ of respondents in this subgroup were also found to have been consumers of these products for $>1$ year, and $93 \%$ consumed these products every day. Also, the majority in this group consumed more than one enriched product per day (76\%).

Respondents were asked if they took the products due to high cholesterol, and if so whether they also took medication for this. In response, $22 \%$ ( $n$ 104) reported taking statin drugs. Unlike the situation in some other EU countries, in Ireland statins are available only on medical prescription. In this subgroup, the mean phytosterol intake was 2.71 (sD 1.44$) \mathrm{g} / \mathrm{d}$ (data not shown). This was significantly higher than the mean phytosterol intake in statin non-users $(2 \cdot 38 \mathrm{~g} / \mathrm{d})(P=0 \cdot 041)$. No significant differences in phytosterol intakes were observed according
Table 4 Characteristics of the intake of phytosterol-enriched products in respondents with intakes $>3.0 \mathrm{~g} / \mathrm{d}$ : Irish consumers of phytosterol-enriched products, 2005

\begin{tabular}{|c|c|c|c|c|c|}
\hline & \multirow[b]{2}{*}{$n$} & \multirow[b]{2}{*}{$\%$} & \multicolumn{3}{|c|}{ Phytosterol intake (g/d) } \\
\hline & & & Mean & SD & Range \\
\hline Total & 106 & 100 & $4 \cdot 64$ & $1 \cdot 36$ & $3 \cdot 07-9 \cdot 84$ \\
\hline \multicolumn{6}{|l|}{ Consumers only } \\
\hline Spreads & 103 & $97 \cdot 2$ & $4 \cdot 66$ & $1 \cdot 37$ & $3.07-9 \cdot 84$ \\
\hline Yoghurt & 24 & $22 \cdot 6$ & $4 \cdot 60$ & $1 \cdot 37$ & $3 \cdot 07-8 \cdot 90$ \\
\hline Yoghurt drinks & 79 & $74 \cdot 5$ & $4 \cdot 80$ & $1 \cdot 44$ & $3 \cdot 17-9 \cdot 84$ \\
\hline Cheese spread & 3 & $2 \cdot 8$ & $3 \cdot 75$ & 0.63 & $3 \cdot 23-4 \cdot 46$ \\
\hline Milk & 3 & $2 \cdot 8$ & $4 \cdot 79$ & $1 \cdot 34$ & $3 \cdot 24-5.60$ \\
\hline \multicolumn{6}{|c|}{ Period of consumption } \\
\hline$<6$ months & 18 & $17 \cdot 0$ & $4 \cdot 31$ & $0 \cdot 82$ & $3 \cdot 17-5 \cdot 96$ \\
\hline 6-12 months & 10 & $9 \cdot 4$ & $4 \cdot 76$ & $1 \cdot 35$ & $3 \cdot 43-6 \cdot 99$ \\
\hline$>1$ year & 78 & $73 \cdot 6$ & $4 \cdot 69$ & $1 \cdot 45$ & $3 \cdot 07-9 \cdot 84$ \\
\hline \multicolumn{6}{|c|}{ No. of days per week that products are consumed } \\
\hline $1-3 \mathrm{~d} /$ week & 3 & $2 \cdot 8$ & $4 \cdot 02$ & 0.68 & $3 \cdot 25-4 \cdot 54$ \\
\hline $4-6 \mathrm{~d} /$ week & 4 & $3 \cdot 8$ & $4 \cdot 59$ & $0 \cdot 78$ & $3 \cdot 92-5 \cdot 52$ \\
\hline $7 \mathrm{~d} /$ week & 99 & $93 \cdot 4$ & $4 \cdot 66$ & $1 \cdot 39$ & $3 \cdot 07-9 \cdot 84$ \\
\hline \multicolumn{6}{|c|}{ No. of product types consumed per day } \\
\hline $1 \mathrm{product} / \mathrm{d}$ & 25 & $23 \cdot 6$ & $4 \cdot 19$ & 0.79 & $3 \cdot 43-6 \cdot 37$ \\
\hline 2 products $/ \mathrm{d}$ & 65 & $61 \cdot 3$ & $4 \cdot 75$ & $1 \cdot 50$ & $3 \cdot 07-9 \cdot 84$ \\
\hline 3 products/d & 16 & $15 \cdot 1$ & $4 \cdot 87$ & $1 \cdot 36$ & $3 \cdot 17-8 \cdot 90$ \\
\hline \multicolumn{6}{|l|}{ Brand loyalty } \\
\hline Yes & 68 & $64 \cdot 2$ & 4.55 & $1 \cdot 31$ & $3 \cdot 07-8 \cdot 90$ \\
\hline No & 38 & $35 \cdot 8$ & $4 \cdot 78$ & $1 \cdot 44$ & $3 \cdot 17-9 \cdot 84$ \\
\hline \multicolumn{6}{|c|}{ Does the consumer read the label? } \\
\hline Yes & 56 & $52 \cdot 8$ & $4 \cdot 63$ & $1 \cdot 15$ & $3 \cdot 07-7 \cdot 47$ \\
\hline No & 50 & $47 \cdot 2$ & $4 \cdot 64$ & $1 \cdot 57$ & $3 \cdot 17-9 \cdot 84$ \\
\hline \multicolumn{6}{|c|}{ Awareness of importance of fruit and vegetables } \\
\hline Aware & 45 & $42 \cdot 5$ & $4 \cdot 68$ & $1 \cdot 25$ & $3 \cdot 07-7 \cdot 88$ \\
\hline Unaware & 61 & $57 \cdot 5$ & $4 \cdot 60$ & $1 \cdot 44$ & $3 \cdot 17-9 \cdot 84$ \\
\hline
\end{tabular}

to gender, age group, length of time consuming products, whether the label was read, or method of introduction to the products $(P>0 \cdot 05)$.

\section{Discussion}

The present study is the first to examine consumption patterns of phytosterol-enriched products in the population of Ireland. Mean phytosterol intake in this sample was $2.45 \mathrm{~g} / \mathrm{d}$, which corresponds with current recommendations $^{(11)}$ that intakes of phytosterols should be within the range of $1.5-3.0 \mathrm{~g} / \mathrm{d}$. Even though it was not feasible as part of the study to measure the decrease in serum cholesterol levels, the results proved that the correct target populations (i.e. those $>45$ years of age and those with high cholesterol) are taking these products and that most (54\%) are taking the correct quantity according to SCF recommendations.

Although mean intakes rested within this recommended range, analysis of the upper intake distribution revealed that $10 \%$ of the sample had daily phytosterol intakes of $4.4 \mathrm{~g}$ or more. These findings differ from the conclusions of Unilever's PLM study ${ }^{(9)}$, which found that intakes were lower than the original anticipated intakes of $1 \cdot 6-2 \cdot 4 \mathrm{~g} / \mathrm{d}$. However, the Unilever PLM study investigated phytosterols from enriched spreads only. A study 
by Hendriks et $a l^{(12)}$ found no adverse effects of phytosterol intakes of $1.6 \mathrm{~g} / \mathrm{d}$ for 1 year. However, owing to the lack of long-term studies (i.e. $>5$ years), there is a paucity of information from which to draw conclusions about the effects of long-term intakes of phytosterols in man. A recent review by Patel and Thompson ${ }^{(13)}$ suggests that more definitive studies are required to explore the relationship between phytosterol levels and potential adverse effects in the general population.

The average phytosterol intake for men $(2 \cdot 71 \mathrm{~g} / \mathrm{d})$ was significantly higher than that for women $(2 \cdot 29 \mathrm{~g} / \mathrm{d})$. This may be due to larger portion sizes of phytosterol-enriched foods consumed by males. For direct comparisons, currently no other studies exist that have examined phytosterol levels from enriched sources in populations consuming phytosterols from as many product types as explored in the present study. However, studies on prospective intakes from multiple phytosterol-enriched products have been carried out. One simulation study based in The Netherlands (using hypothesised replacement of foods such as margarine, cheese, yoghurt, meats and salad dressing) anticipated intakes above the 90th percentile in men to exceed $8.6 \mathrm{~g} / \mathrm{d}^{(14)}$. This corresponds to the maximum intake of $8.9 \mathrm{~g} / \mathrm{d}$ achieved for males in the higher intake level (i.e. above the 90th percentile) in the present study. A similar study of prospective phytosterol intake in Germany (using foods such as margarine, milk, cheeses, meats and bread) anticipated a maximum intake of $13 \mathrm{~g} / \mathrm{d}^{(15)}$. This level of daily phytosterol intake was not reached by any consumer within the total sample population of the present study; however, those studies used more enriched foods than we examined herein.

Although no significant differences were observed in intakes of phytosterols between the different age groups, the majority of consumers were $>45$ years old $(81 \%)$, which is the appropriate target group for these products ${ }^{(9)}$. Respondents with higher education levels were found to have the lowest phytosterol intakes $(2 \cdot 14 \mathrm{~g} / \mathrm{d})$; a possible reason for this is that higher educated people may be more aware of the recommended intakes of phytosterol-enriched products required for efficiency (i.e. to have a cholesterollowering effect). This may be due to better interpretation of intake guidelines contained on the food label, as it has been shown that those with higher education levels have greater comprehension of information on food labels ${ }^{(16,17)}$. Interestingly, the majority of people were introduced to these products through the medium of advertising (53\%), while only $14.5 \%$ were introduced by their doctor despite the fact that these products are targeted at those with a specific medical condition (i.e. high/raised cholesterol levels). However, most people reported consuming these products owing to having high cholesterol (61\%), which suggests that consumers are aware of the function of the product. This result agrees with the findings of the Unilever PLM study, i.e. that the target population is in fact consuming phytosterol-enriched products ${ }^{(9)}$.
As the aim of the present study was to characterise consumption patterns of phytosterol-enriched products among consumers, they were questioned on the period of consumption, on the number of days of the week products were consumed and on the number of product types consumed. The majority responded that they had been consumers for $>1$ year (58\%), that they consumed these products every day of the week (90\%) and that they consumed one product type per day (69\%). A study by Simojoki et $a l^{(18)}$ in Finland also found evidence of a large subgroup of long-term users of plant sterol ester margarine. In the present study, those who reported consuming enriched products for $>1$ year were also more likely to have phytosterol intakes $>3.0 \mathrm{~g} / \mathrm{d}(29 \%)$ than those who reported consuming them over a shorter period of time ( $12 \%$ for $<6$ months), which indicates that long-term intakes of phytosterols at levels $>3.0 \mathrm{~g} / \mathrm{d}$ is a pattern in our population. The most accessible vehicle on information about portion size and other safety advice for the consumer of phytosterol-enriched products is the food label. Therefore we asked respondents about label reading; while the majority reported that they read the label $(62 \%)$, it was also found that $62 \%$ of the sample were unaware of the recommendation to include regular consumption of fruit and vegetables when consuming these products to help maintain carotenoid levels ${ }^{(19-22)}$.

When the contribution of different product types to intakes of phytosterols was investigated, it was found in the total sample that intake of phytosterols was highest from spreads (at $1.33 \mathrm{~g} / \mathrm{d}$ ), followed closely by one-a-day yoghurt drinks (at $1 \cdot 14 \mathrm{~g} / \mathrm{d}$ ). However, when consumers of these product types were examined, intakes were highest from one-a-day yoghurt drinks (although the number of consumers of enriched spreads was the highest of all product types). Therefore, when there is more than one phytosterol-enriched product type available on the market, it is important that intakes from all sources are examined.

As most studies that have looked at intakes of phytosterols from enriched sources have examined only one product type (usually yellow fat spreads), the intake of those respondents who only consumed one product in total was examined. Spreads and one-a-day yoghurt drinks were the main product types that were consumed on their own, with the phytosterol intake from spreads alone at $1.99 \mathrm{~g} / \mathrm{d}$ (corresponding to an average daily portion of $28 \mathrm{~g}$ of enriched spread). This consumption of spreads is higher than that reported in a recent Dutch study by Wolfs et $a l^{(10)}$, where spread consumption ranged from $9 \mathrm{~g} / \mathrm{d}$ (stanol-enriched spread) to $15 \mathrm{~g} / \mathrm{d}$ (sterol-enriched spread). A median consumption per household of $15-18 \mathrm{~g} / \mathrm{d}$ was observed in the Unilever PLM study ${ }^{(9)}$. The reason for the higher enriched spread consumption in the present study is that Irish people are in general high consumers of spreads, and these customary dietary patterns are continued with the phytosterol-enriched product (in the 
1997-1999 national Irish food consumption survey, intakes of yellow fat spreads from all sources was $\left.32 \mathrm{~g} / \mathrm{d}^{(23)}\right)$. Apart from one-a-day yoghurt drinks, the other four product types on the Irish market need to be consumed in three portions per day in order to meet recommended phytosterol intakes for achieving a functional effect. Therefore, we examined the consumption patterns of these products. All of the five product types were consumed in a 'mix-and-match' fashion, which is important for consideration in a safety assessment of these products. Although each one-a-day yoghurt drink provides the correct quantity of phytosterols to have a cholesterol-lowering effect, they were found to be consumed in combination with other enriched products (e.g. from a total of 272 consumers of yoghurt drinks, there were 133 individuals who also consumed enriched spreads). This indicates that a lot of people are unaware of the correct portions of these products to be consumed in order to have a functional effect.

As the effects of long-term intake of high phytosterol levels are unknown, we decided to analyse the subgroup of individuals who had intakes higher than those recommended by the SCF. It was found that the majority of this subgroup were consuming high intakes of phytosterols for $>1$ year $(74 \%$, with mean intakes of $4.69 \mathrm{~g} / \mathrm{d}$ ) and most of group (61\%) consumed two product types daily (i.e. appeared to mix and match product types on the same day). This indicates that there is a large subgroup in the Irish population who are established consumers of these enriched products and who are consuming phytosterol intakes above the recommended levels over a relatively long period of time.

Another area where there is still some uncertainty in the literature is the impact of consuming phytosterol-enriched products when simultaneously taking cholesterollowering drugs, such as statins. Many studies have reported findings of an additive effect between statin drugs and phytosterols ${ }^{(24-26)}$ although some studies have not shown this ${ }^{(27,28)}$. There is evidence that plant sterols are increased in serum during statin treatment, and that high plant sterol levels are an independent coronary risk factor in the long term ${ }^{(29)}$. However, as stated on the food label of these products, individuals taking statins should only consume phytosterol-enriched foods under medical supervision $^{(22)}$. A total of 104 (22\%) respondents reported taking statins, and their mean phytosterol intake was significantly higher than that of the statin non-users. Although the reasons for this greater intake of phytosterols from enriched sources cannot be deduced directly from the present study, it may be inferred that people who have been diagnosed with high cholesterol and who are actively managing it through medication may also perceive that greater consumption of phytosterolenriched foods will be of extra benefit. As the effect of combining statins and phytosterols has been shown to be additive, educating people about the recommended portions of phytosterol-eniched products is prudent. It was interesting to note that although these individuals were taking statins, only 19\% were introduced to the phytsterolenriched products by their doctor, with the majority reporting that they were introduced via advertising.

A drawback to the present study was that information on people who did not want to take part in the survey was not recorded. However, the response rate was deemed to be very high according to the fieldworkers, who reported that the great majority of consumers of phytosterol-enriched products agreed to participate. Another limitation is that we had to rely on the ability of the consumer to provide us with accurate information regarding their intake of phytosterol-enriched foods. Under- and over-reporting may have occurred when carrying out the survey due to misunderstanding or memory loss. Attempts to prevent this included our detailed interview-assisted survey questionnaire with photographs of product types and portion sizes. Also, sampling occurred in different geographical and socioeconomic locations, and at different times during the day. Hence every effort was made to collect as comprehensive and accurate information as possible.

\section{Conclusion}

The present study is the first to specifically examine consumption patterns of all phytosterol-enriched foods in the Irish population. It showed that, for the most part, phytosterol intakes were within recommended efficacious levels in the Irish population. In addition, it was found that the target population was consuming phytosterol-enriched products. However, there appeared to be an established subgroup that had phytosterol intakes greater than the current recommendations for $>1$ year. It was also found that a high proportion of consumers of phytosterolenriched foods were not aware of the importance of also consuming fruit and vegetables regularly to prevent a reduction in plasma carotenoid levels. The range of phytosterol-enriched products on the Irish and EU market is expanding constantly, and the present study indicates that consumption patterns of these products are dynamic. Therefore future studies may need to be completed in other countries where enriched products are available to determine the actual intakes and consumption patterns of these products in different settings.

\section{Acknowledgements}

Conflict of interests: There are no known conflicts of interest.

Source of funding: The study was funded under the EU FP6 project Noforisk: 'Quantitative risk assessment strategies for novel foods' (FP6-506387). 
Author contributions: A.H. prepared the final drafts of the manuscript; A.H. and E.D. outlined the study protocol from the initial stages, supervised the collection of data and conducted the final analysis; J.J. and C.O'C. collected the data and conducted data entry; M.J.G. provided direction and guidance to the study.

\section{References}

1. Heinemann T, Kullak-Ublick GA, Pietruck B \& von Bergmann K (1991) Mechanisms of action of plant sterols on inhibition of cholesterol absorption. Eur J Clin Pharmacol 40, Suppl., 59-63.

2. Ling WH \& Jones PJ (1995) Dietary phytosterols: a review of metabolism, benefits and side effects. Life Sci 57, 195-206.

3. Nguyen TT (1999) The cholesterol-lowering action of plant stanol esters. J Nutr 129, 2109-2112.

4. Ostlund RE, Spilburg CA \& Stenson WF (1999) Sitostanol administered in lecithin micelles potently reduces cholesterol absorption in humans. Am J Clin Nutr 70, 826-831.

5. Law M (2000) Plant sterol and stanol margarines and health. Lancet 320, 861-864.

6. Miettinen TA, Puska P, Gylling H, Vanhanen H \& Vartiainen E (1995) Reduction of serum cholesterol with sitostanol-ester margarine in a mildly hypercholesterolemic population. N Engl J Med 333, 1308-1312.

7. Hallikainen MA, Sarkkinen ES \& Uusitupa IJ (2000) Plant stanol esters affect serum cholesterol concentrations of hypercholesterolemic men and women in a dose-dependant manner. J Nutr 130, 767-776.

8. de Jong A, Plat J \& Mensink RP (2003) Metabolic effects of plant sterols and stanols (review). J Nutr Biochem 14, 362-369.

9. Scientific Committee on Food (2002) Opinion of the Scientific Committee on Food on a report on post launch monitoring of 'yellow fat spreads with added phytosterol esters' (expressed on 26 September 2002). http:// ec.europa.eu/food/fs/sc/scf/out144_en.pdf (accessed January 2007).

10. Wolfs M, de Jong N, Ocke MC, Verhagen H \& Verschuren WM (2006) Effectiveness of customary use of phytosterol/ stanol enriched margarines on blood cholesterol lowering. Food Chem Toxicol 44, 1682-1688.

11. Scientific Committee on Food (2002) General view of the Scientific Committee on Food on the long-term effects of the intake of elevated levels of phytosterols from multiple dietary sources, with particular attention to the effects of $\beta$-carotene (expressed on 26 September 2002). http:// ec.europa.eu/food/fs/sc/scf/out143_en.pdf (accessed January 2007).

12. Hendriks HFJ, Brink EJ, Meijer GW, Princen HMG \& Ntanios FY (2003) Safety of long-term consumption of plant sterol esters-enriched spread. Eur J Clin Nutr 57, 681-692.

13. Patel MD \& Thompson PD (2006) Phytosterols and vascular disease. Atherosclerosis 186, 12-19.

14. de Jong N, Pijpers L, Bleeker JK \& Ocke MC (2004) Potential intake of phytosterols/stanols: results of a simulation study. Eur J Clin Nutr 58, 907-919.
15. Kuhlmann K, Lindtner O, Bauch A, Ritter G, Woerner B \& Niemann B (2005) Simulation of prospective phytosterol intake in Germany by novel functional foods. BrJ Nutr $\mathbf{9 3}$, 377-385.

16. Satia JA, Galanko JA \& Neuhouser ML (2005) Food nutrition label use is associated with demographic, behavioural, and psychosocial factors and dietary intake among African Americans in North Carolina. J Am Diet Assoc 105, 392-402.

17. Rothman RL, Housam R, Weiss H, Davis D, Gregory R, Gebretsadik T, Shintani A \& Elasy TA (2006) Patient understanding of food labels: the role of literacy and numeracy. Am J Prev Med 31, 391-398.

18. Simojoki M, Luoto R, Uutela A, Boice JD, McLaughlin JK \& Puska P (2003) Consistency of use of plant stanol ester margarine in Finland. Public Health Nutr 7, 63-68.

19. Gylling H, Puska P, Vartiainen E \& Miettinen TA (1999) Retinol, vitamin D, carotenes and $\alpha$-tocopherol in serum of a moderately hypercholesterolemic population consuming sitostanol ester margarine. Atherosclerosis 145, 279-285.

20. Noakes M, Clifton P, Ntanios F, Shrapnel W, Record I \& McInerny J (2002) An increase in dietary carotenoids when consuming plant sterols or stanols is effective in maintaining plasma carotenoid concentrations. Am J Clin Nutr $\mathbf{7 5}$, 79-86.

21. Colgan HA, Floyd S, Noone EJ, Gibney MJ \& Roche HM (2004) Increased intake of fruit and vegetables and a lowfat diet, with and without low-fat plant sterol-enriched spread consumption: effects on plasma lipoprotein and carotenoid metabolism. J Hum Nutr Diet 17, 561-569.

22. European Commission (2004) Commission Regulation (EC) No 608/2004 of 31st March 2004 concerning the labelling of foods and food ingredients with added phytosterols, phytosterol esters, phytostanols and/or phytostanol esters. Official Journal of the European Union 1.4.2004, L97/ 44-L97/45.

23. Duffy E, Hearty AP \& Gibney MJ (2005) Modelling intakes of phytosterols to aid understanding of actual intakes and to provide more accurate estimates for post launch monitoring. S Afr J Clin Nutr 18, Suppl. 1, 52.

24. Blair SN, Capuzzi DM, Gottlieb SO, Nguyen T, Morgan JM \& Cater NB (2000) Incremental reduction of serum total cholesterol and low-density lipoprotein cholesterol with the addition of plant stanol ester-containing spread to statin therapy. Am J Cardiol 86, 46-52.

25. Katan MB, Grundy SM, Jones P, Law M, Miettinen T \& Paoletti R (2003) Efficacy and safety of plant stanols and sterols in the management of blood cholesterol levels. Mayo Clin Proc 78, 965-978.

26. de Jong N, Simojoki M, Laatikainen T, Tapanainen $\mathrm{H}$, Valsta L, Lahti-Koski M, Uutela A \& Vartiainen E (2004) The combined use of cholesterol-lowering drugs and cholesterol-lowering bread spreads: health behaviour data from Finland. Prev Med 39, 849-855.

27. Neil HAW, Meijer GW \& Roe LS (2001) Randomised controlled trial of use by hypercholesterolaemic patients of a vegetable oil sterol-enriched fat spread. Atherosclerosis 156, 329-337.

28. Miettinen TA \& Gylling H (2003) Synthesis and absorption markers of cholesterol in serum and lipoproteins during a large dose of statin treatment. Eur J Clin Invest 33, 976-982.

29. Miettinen TA \& Gylling H (2005) Effect of statins on noncholesterol sterol levels: implications for use of plant stanols and sterols. Am J Cardiol 96, 40-46. 